\title{
Study of Time Lag in a Bioclimatic House Made of Eco
}

\section{Materials}

\author{
Fati Zoma ${ }^{1}$, Toguyeni David Yemboini Kader ${ }^{1 *}$, Abdoulaye OUEDRAOGO ${ }^{2}$ and Jean KOULIDIATI ${ }^{1}$ \\ 1. Laboratory of Physics and Chemistry of Environment, University of Ouagadougou, Ouagadougou, 03 BP 7021, Burkina Faso \\ 2. Laboratory of Thermal and Renewable Energies, University of Ouagadougou, Ouagadougou, 03 BP 7021, Burkina Faso
}

\begin{abstract}
This paper presents a prediction of thermal behavior of bioclimatic building by the mean of time lag. Firstly, we provided locally made materials with commonly known thermal properties. Afterwards, we conducted a simulation of a building free of internal charges on the TRNSYS 16 (Transient system simulation) platform. This simulation has focused on the collection of thermograms concerning the inside and outside surfaces (exposed to solar radiation) temperatures of walls oriented South, East, North and West on the basis of a weather file called Meteonorm. An analysis of the results was conducted which leaded to the conclusion that time lags of East oriented walls is greater than that of the other walls. Furthermore, the simulation confirms that the lower the value of thermal diffusivity is, the greater the corresponding time lag is. Finally, the results of the investigations revealed that the locally designed materials have greater time lag than that of commonly use materials, like concrete. Therefore, they consume less energy as construction materials.
\end{abstract}

Keys words: Time lag, simulation, thermal diffusivity, bioclimatic, TRNSYS (Transient system simulation).

\section{Nomenclature}

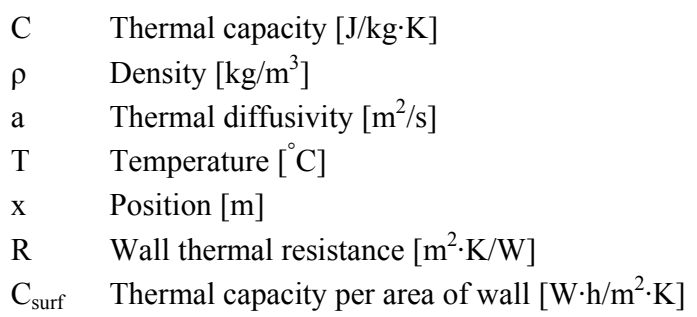

\section{Greek Letters}

$\lambda \quad$ Thermal conductivity $[\mathrm{W} / \mathrm{m} \cdot \mathrm{K}]$

$\psi \quad$ Time lag considering temperatures at determined

$\psi \quad$ Positions [radian]

$\omega \quad$ Angular frequency of the periodical signal [radian/s]

$\tau \quad$ Relative time constant

$\Delta \varphi \quad$ Time lag considering maximum temperatures at front and back of a wall $\left[{ }^{\circ} \mathrm{C}\right]$

\section{Introduction}

In many countries, buildings consume more energy than transport and industry. According to the IEA (International Energy Agency) statistics [1] one can

\footnotetext{
"Corresponding author: Toguyeni David Yemboini Kader,
} Ph.D., research fields: materials and energy efficiency. state that globally, the building sector is responsible for 42 percent of electricity consumption.

The building sector encompasses a diverse set of end use activities, which have different energy use implications. Space heating, space cooling and lighting, which together account for a majority of building energy used in industrialized countries, depend not only on the energy efficiency of temperature control and lighting systems, but also the efficiency of the buildings in which they operate. The importance of energy efficiency in building sector is especially significant in developing countries, owing to rapid new constructions with opportunities to employ efficient materials and best practices.

Given many possibilities to substantially reduce buildings' energy requirements, the potential savings of energy efficiency in the building sector would greatly contribute to a society-wide reduction of energy consumption. Besides, by reducing buildings' energy consumption, a nation can reduce dependency on imported energy and strengthen its strategic position. It is worth to say that moderation of energy-end used in 
buildings will also reduce greenhouse gas emissions and pollution that produced by the combustion of fossil fuels.

One way for the reduction of energy consumption is to provide environmental friendly materials which are suitable to the local challenging climate.

In fact, Toguyeni et al. [2] have studied the influence of local materials used for roof insulation on cooling loads of a typical clay-straw house. After the determination of the thermophysical properties (conductivity, thermal effusivity and density) of these materials by a hot plate method with an analysis of thermograms, in steady and unsteady regimes, the authors through TRNSYS (Transient system simulation) indicated that the clay-straw wall consumes an average of $8 \%$ less energy than the standard clay wall on an annual basis. In addition, Coulibaly O. and Toguyeni D. Y. K. [3] studied the influence of eco materials for roof insulation and fiber-reinforced mortar coatings on cooling loads of a home in dry tropical climate. The walls of the house were made of cinderblock or laterite and the insulating material of a roof panel was made with lime $(24 \%)$, cement $(6 \%)$, water $(50 \%)$ of vegetable fibers hibiscus sabdariffa (tree widespread in Burkina Faso) (16\%) and sugar cane bagasse (4\%). Then, a building was modeled in TRNSYS using climate data from the city of Ouagadougou for the warmer months of the year, namely in March and April. The simulation reveals that the relative differences between heat gains of configurations "breeze block-coating mortar and roof not insulated" and "laterite- fiber-reinforced mortar coating and insulated roof" vary between $15.6 \%$ and $16.8 \%$.

In this paper, we focus on heat transfer in materials in order to predict their thermal behavior like their thermal inertia by the mean of time lag.

\section{Procedure and Method}

\subsection{Data Collection}

The thermal properties used in this study come directly from designed materials and also from the thesis of Lawane [4] and the literature [5].

In Table 1, the term material represents wall made with these materials.

Materials No. 1, 2, 3, 6, 7, 8, 9 and 11 are local materials made by vibrating soil $(48 \%$ of grains with diameter inferior to $80 \mu \mathrm{m}$ and $52 \%$ of grains with diameter superior to $80 \mu \mathrm{m}$ ) mixed with vegetal fibers of hibiscus cannabis. Material 4 from Lawane's thesis, is laterite. Material 5 and 10 are concrete made but with the specification that they are used in walls made respectively of hollow bricks and solid bricks

\subsection{Time Lag}

Time lag, as shown in Fig 1, is the time difference corresponding to the highest temperatures recorded on both heated and non heated sides of a wall.

Contrary to thermal conductivity, thermal diffusivity which is related to the thermal inertia is a dynamic

Table 1 Thermal properties database.

\begin{tabular}{lllll}
\hline MATERIAL No. & $\lambda[\mathrm{W} / \mathrm{m} \cdot \mathrm{K}]$ & $\mathrm{C}[\mathrm{J} / \mathrm{kg} \cdot \mathrm{K}]$ & $\rho\left[\mathrm{kg} / \mathrm{m}^{3}\right]$ & $\mathrm{a}\left[\mathrm{m}^{2} / \mathrm{s}\right] \pm 10 \%$ \\
\hline 1 & 0.6 & $1,526.3$ & $1,565.91$ & $2.51 \mathrm{E}-07$ \\
2 & 0.43 & $1,238.4$ & $1,360.32$ & $2.55 \mathrm{E}-07$ \\
3 & 0.92 & $1,472.3$ & $1,790.19$ & $3.49 \mathrm{E}-07$ \\
4 & 0.51 & 795 & 1,820 & $3.52 \mathrm{E}-07$ \\
5 & 0.4 & 880 & 1,200 & $3.79 \mathrm{E}-07$ \\
6 & 0.483 & 856.1 & $1,488.5$ & $3.79 \mathrm{E}-07$ \\
7 & 0.49 & 812.2 & $1,530.89$ & $3.94 \mathrm{E}-07$ \\
8 & 0.46 & 762.2 & $1,506.23$ & $4.01 \mathrm{E}-07$ \\
9 & 0.692 & 876.3 & $1,699.59$ & $4.65 \mathrm{E}-07$ \\
10 & 0.85 & 817.29 & 1,850 & $5.62 \mathrm{E}-07$ \\
11 & 0.8 & 709 & $1,810.61$ & $6.23 \mathrm{E}-07$ \\
\hline
\end{tabular}




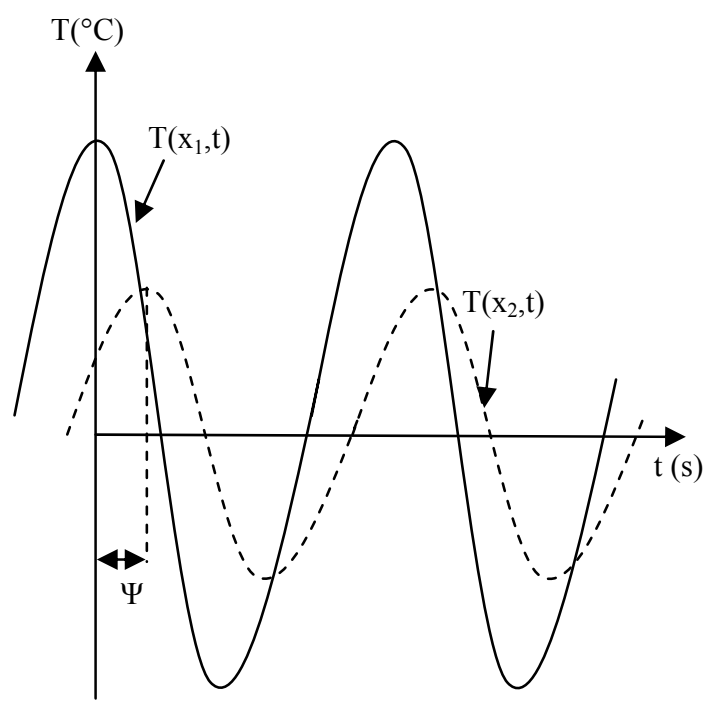

Fig. 1 Sinusoidal evolution of temperature.

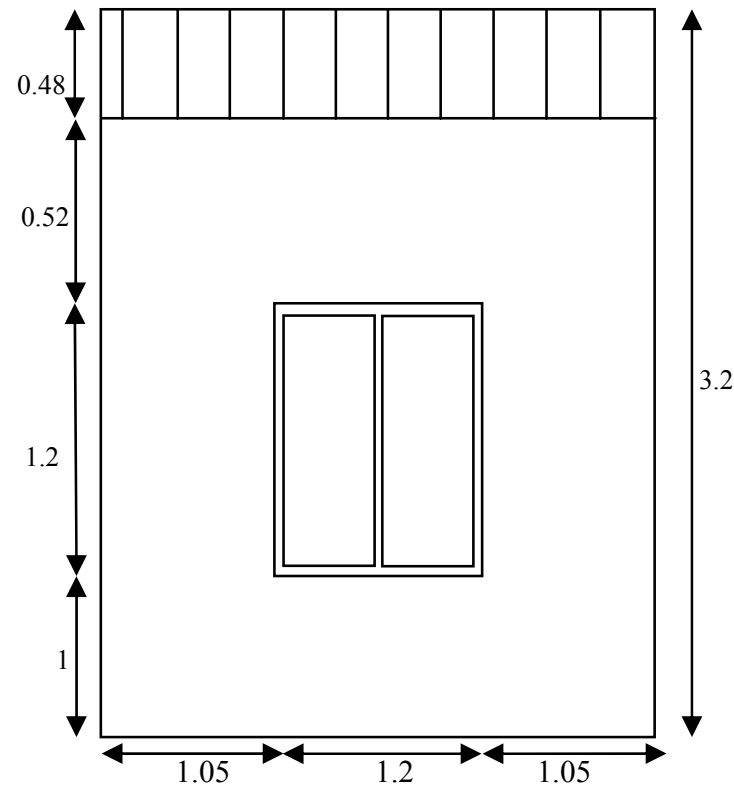

Fig. 2 Back facade/North oriented.

property. In fact, when solar radiations hit a wall, the wall behaves like a semi infinite environment. At first, the wall stores the heat to its capacity and then releases it on the non heated side. During the storage, the temperature on the heated side is increasing while during the releasing of stored heat the other side temperature is increasing: hence the concept of time lag.

Some studies have already been done. For instance, Maréchal and Devisme [6] proposed a model based on a frequency dynamic system:

$$
\Psi=\left(\mathrm{x}_{2}-\mathrm{x}_{1}\right) \sqrt{\frac{\omega}{2 \times a}}
$$

where, $\Psi$ (radian): time lag considering temperatures at positions $\mathrm{x}_{1}=0$ and $\mathrm{x}_{2} \neq 0 ; \omega(\operatorname{radian} / \mathrm{s})$ : angular frequency of the periodical signal; a $\left[\mathrm{m}^{2} / \mathrm{s}\right]$ : thermal diffusivity.

However, this method assumes that the signal is periodical which in reality is difficult to get. In fact, the temperature is a non steady parameter. Hence this model (Eq. (1)) does not take into account the environmental conditions which are really crucial in thermal behavior study.

A more recent formula of a wall time lag, based on a transient system, is given by Roux J. J. [7]:

$$
\psi=\sqrt{\pi \times \tau}
$$

where, $\Psi$ (radian): time lag; $\tau=\left(\mathrm{R} \times \mathrm{C}_{\text {surf }}\right) / 24$ : relative time constant; $\mathrm{R}\left(\mathrm{m}^{2} \cdot \mathrm{K} / \mathrm{W}\right)$ : wall thermal resistance; $\mathrm{C}_{\text {surf }}\left(\mathrm{W} \cdot \mathrm{h} / \mathrm{m}^{2} \cdot \mathrm{K}\right)$ : thermal capacity per area of wall.

\section{Modeling with TRNSYS 16.00 .0036}

\subsection{Description of the Building}

The thermal zone for this study, Figs. 2-4, consists of four homogeneous walls (thickness $0.15 \mathrm{~m}$ ) free of coating, a roof and a floor. The weather database applied is Meteonorm, which is already provided in TRNSYS 16.

\subsection{Internal Charges}

We intend to study a bioclimatic building. For this, the simulated model takes into account no air conditioning, no equipment. Only natural infiltration is accounted, in other terms environmental conditions only. To this end, retained constant infiltration rate value of $0.735 \mathrm{vol} / \mathrm{h} \mathrm{[5]}$.

\subsection{Simulation Results and Discussion}

The parameters simulated in TRNSYS are the inside and outside surface temperatures of each wall per hour per day for a whole year. From these results we calculate 


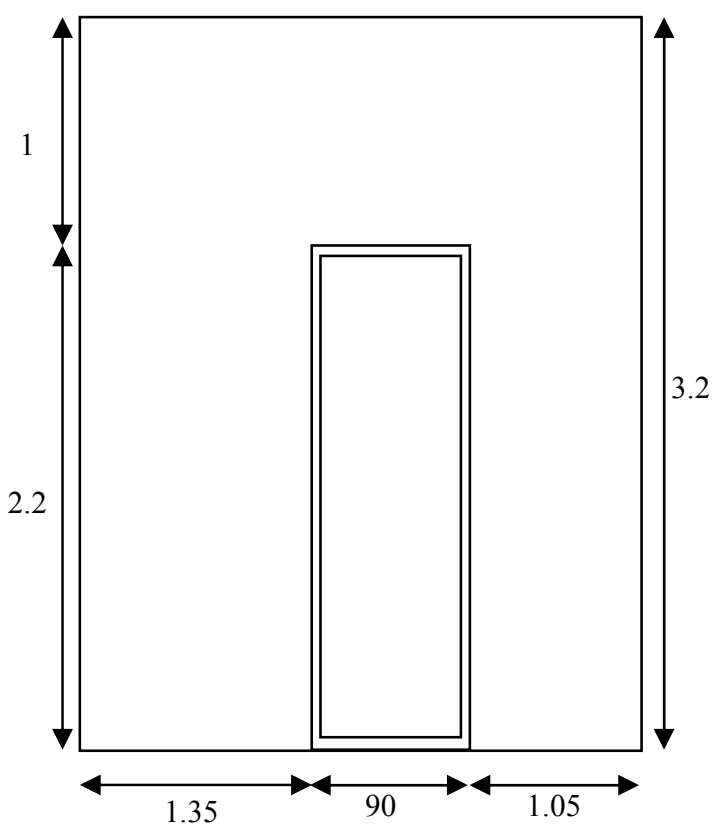

Fig. 3 Front facade/South oriented.

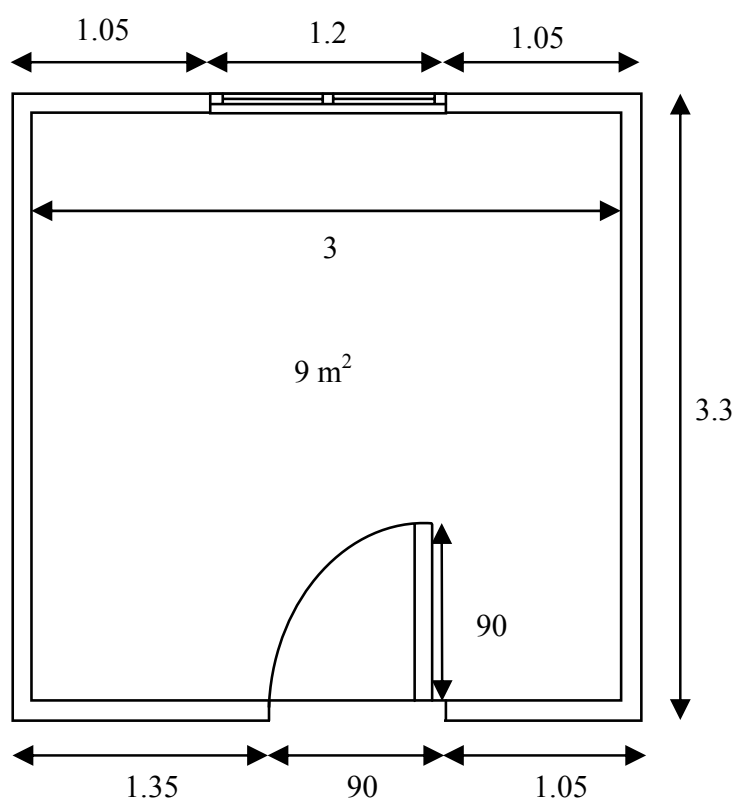

Fig. 4 Plan of the thermal zone.

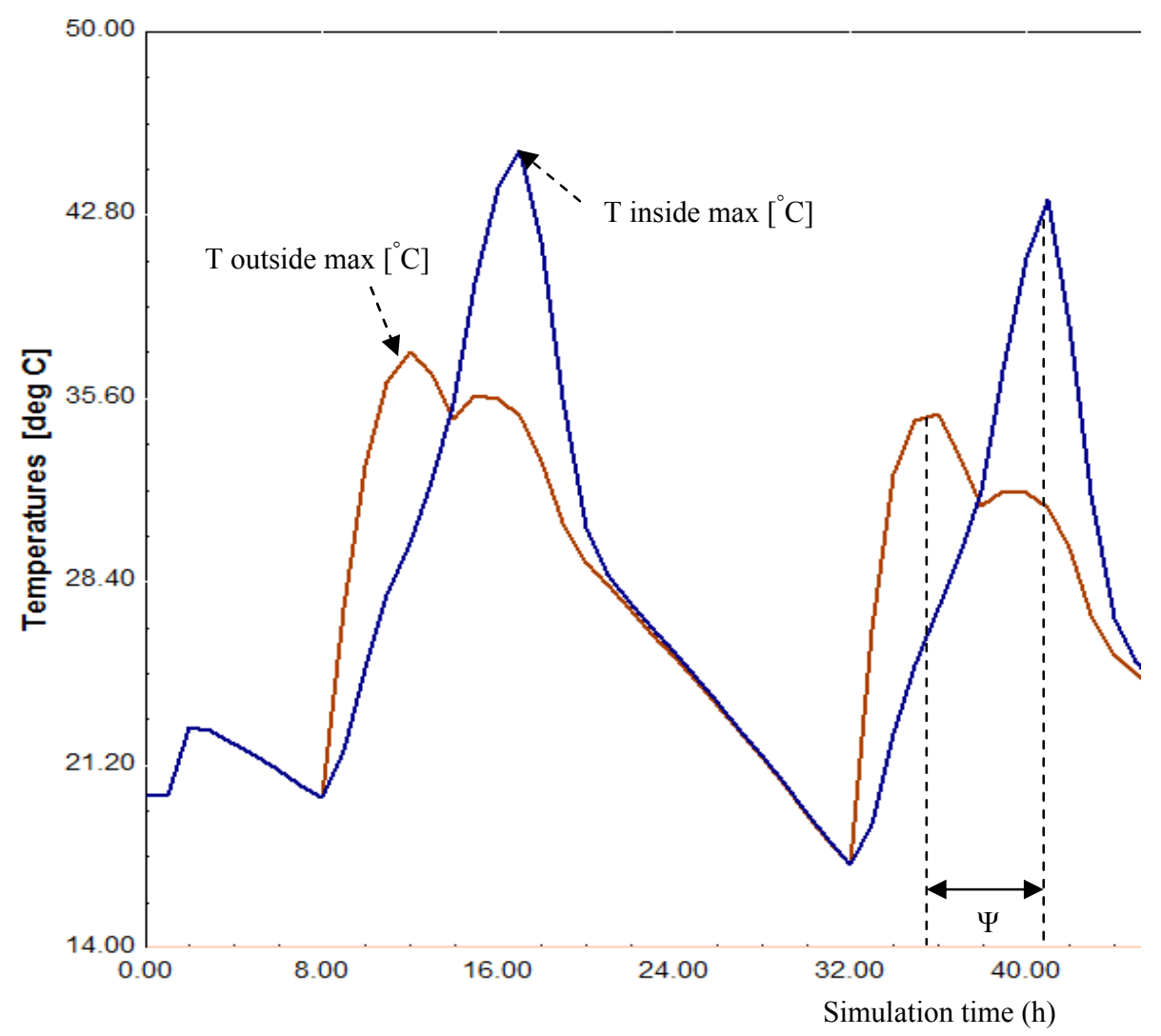

Fig. 5 Example of simulation on TRNSYS 16 (wall East oriented).

the mean time lag depending on the orientation and the period of year.

Figs. 6-9 show the time lag $(\Delta \varphi)$ of walls made of materials in Table 1, for orientations East, South, North, for specific months (Jan., Apr. and Aug.) according to their thermal diffusivity. 


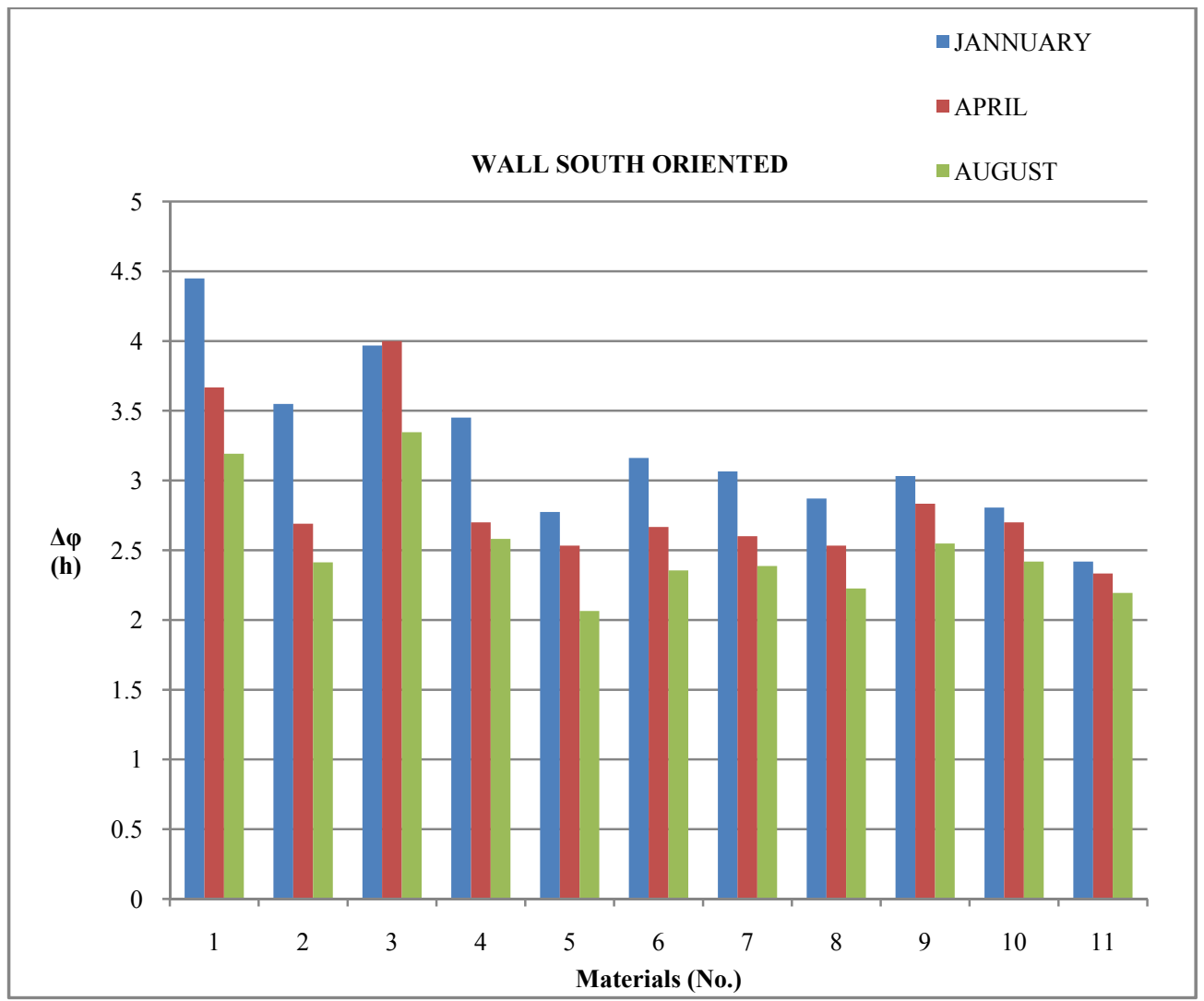

Fig. 6 Materials time lags/South.

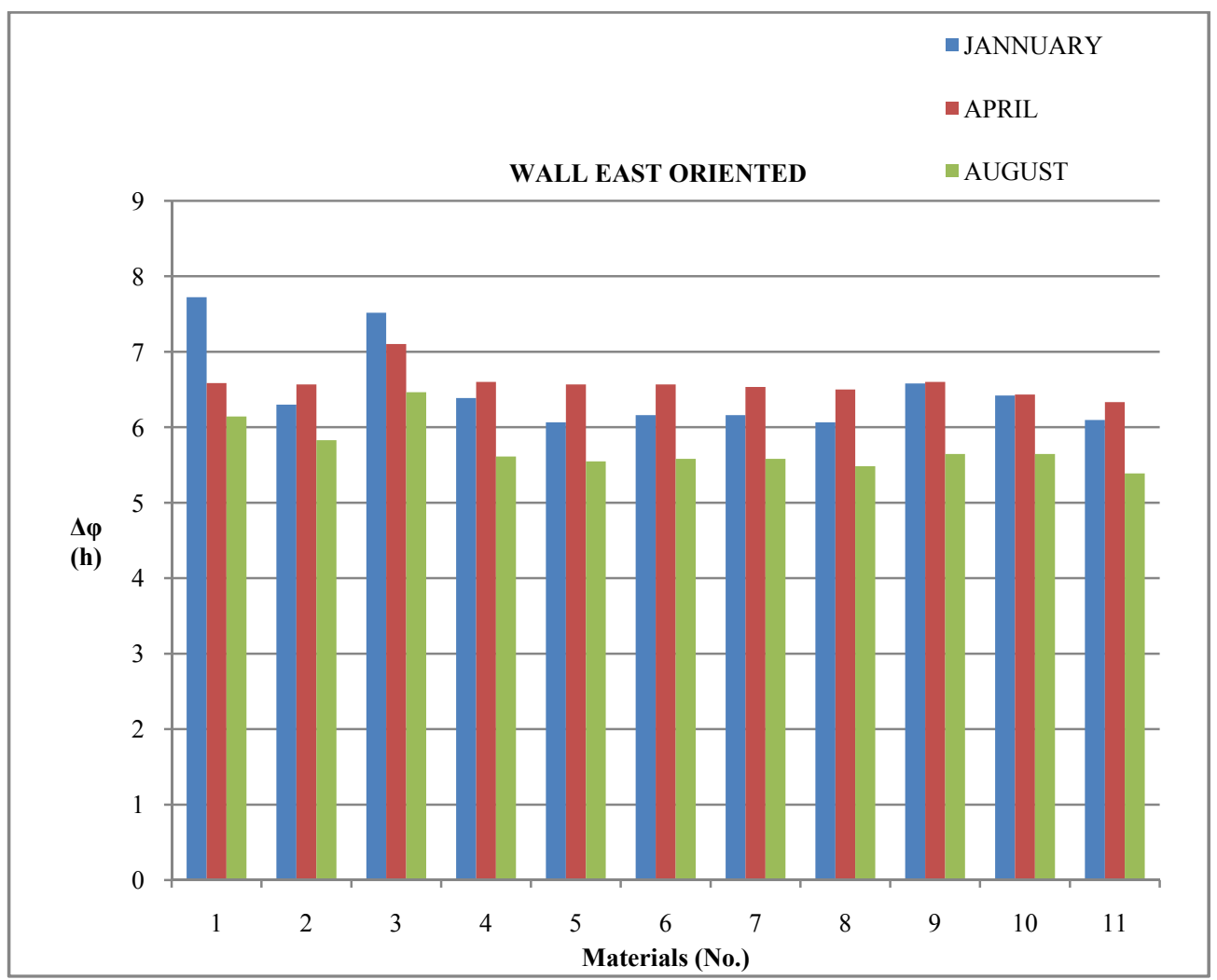

Fig. 7 Materials time lags/East. 


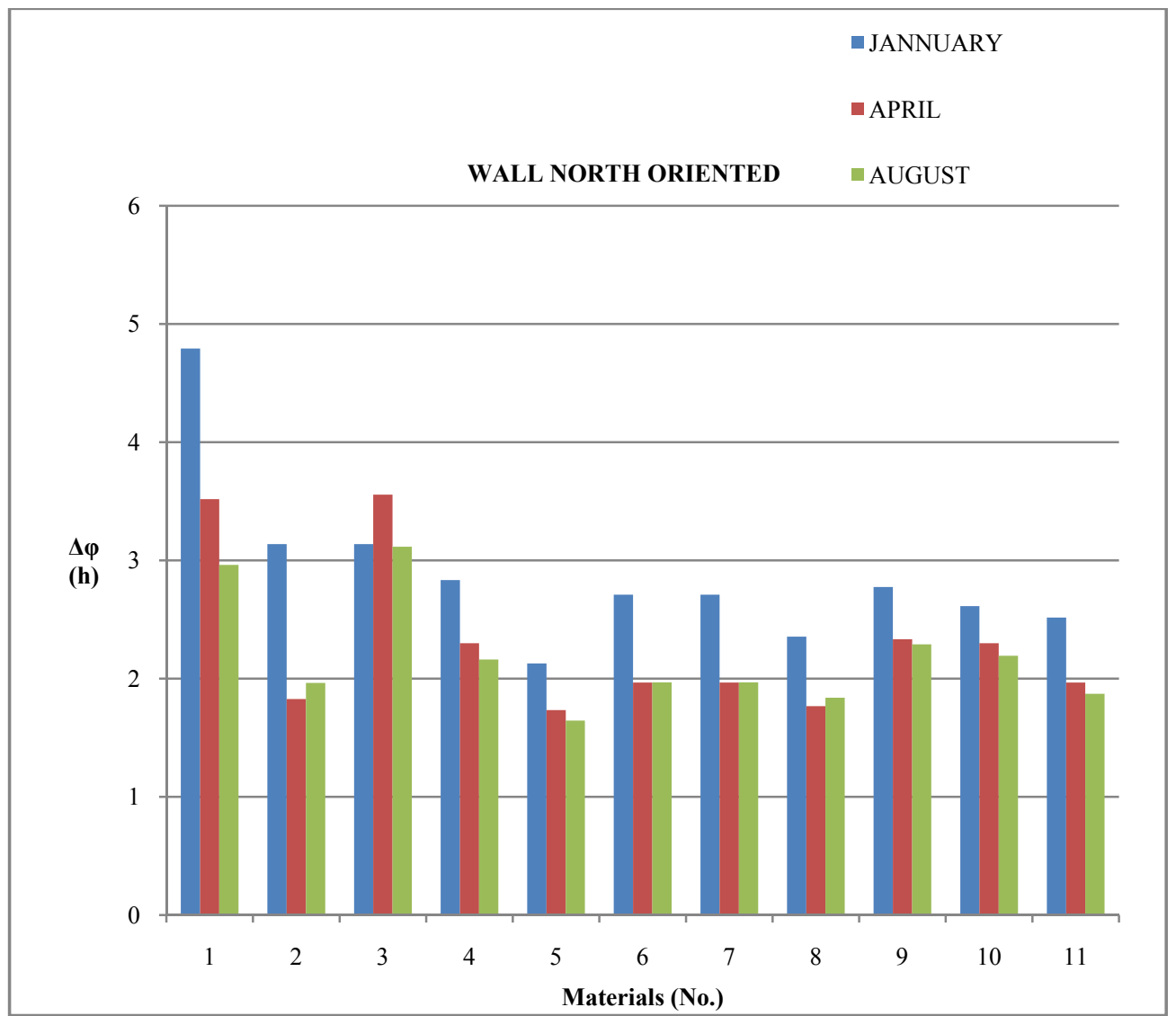

Fig. 8 Materials time lags/North.

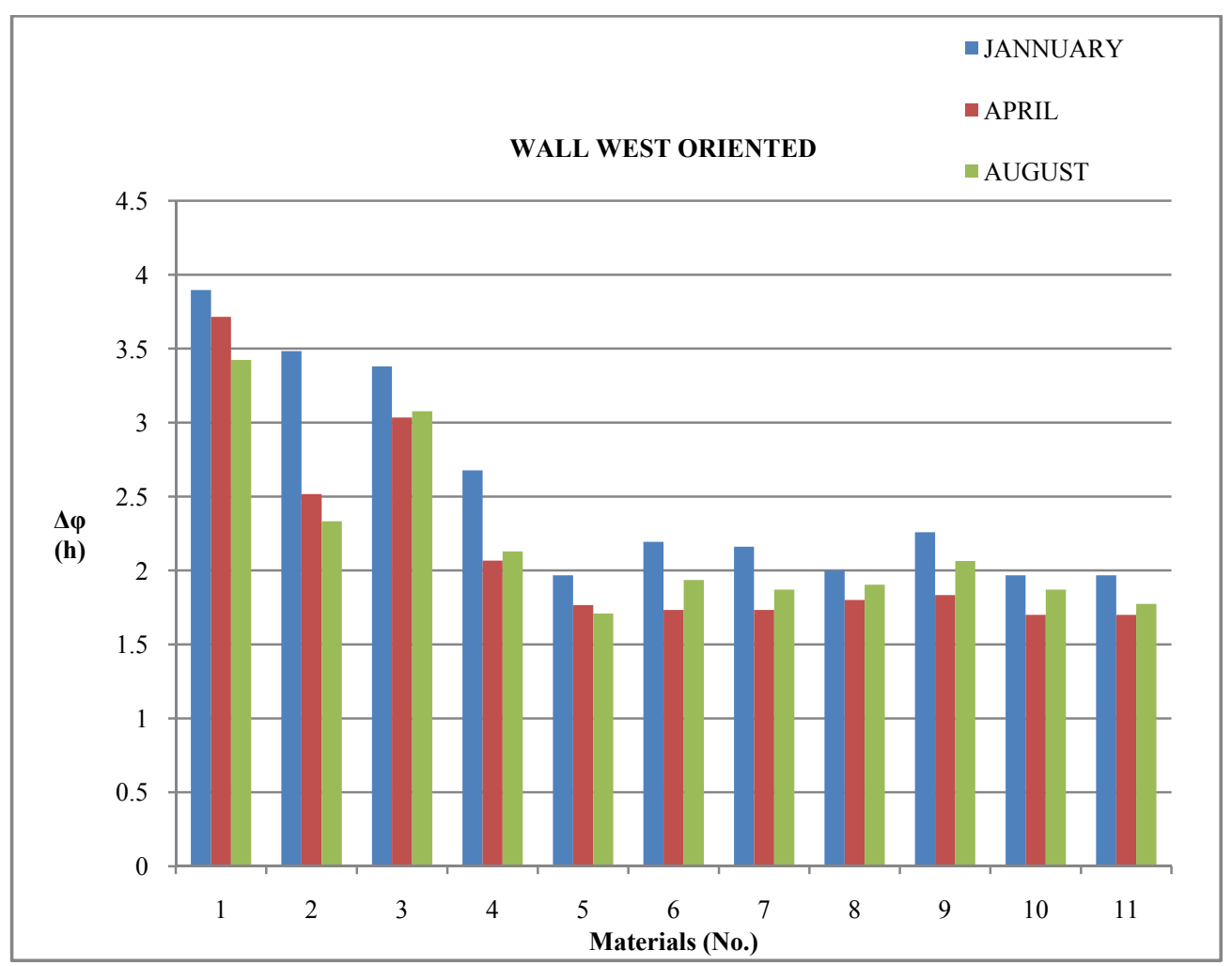

Fig. 9 Materials time lags/West. 
We can see that the time lag is relatively low. Actually, in Buildings the comfort temperature depends on many factors such as the envelop radiations which are related to the thermal inertia of the envelop. Indeed, thermal equilibrium involves the participation of radiations from all four walls including the roof [8]. This resulting phenomenon therefore influences the inside temperature of the walls. As a result, for instance a wall facing West side, that receives little solar radiation, sees its inside temperature climbs faster: it is called thermal amplitude mitigation.

Moreover, Figs. 6-9 show that the time lags $(\Delta \varphi)$ for walls East oriented are in general greater. In fact, the measures of solar radiations that strike walls have revealed that depending on the wall orientation and the moment of the day, the quantity of received solar radiations is different [5]. It is specified that East oriented walls, exposed to solar radiation up to a maximum of $5 \mathrm{~h}$, sees the solar insolation decreasing due to the path of sun. At the same time South and West oriented walls undergo an increase of solar insolation. That means that outside temperature of East oriented wall reaches his maximum earlier than the other walls. Therefore, in addition to the amplitude mitigation on walls interior temperatures, $\Delta \varphi$ for walls East oriented are the greatest.

We can also note that material 2 has greater $\Delta \varphi$ than materials 5 and 10 all the time. Indeed, in physics, it is understandable that the time lag schedule in a homogeneous wall is strongly dependent on the thermal diffusivity which is the speed with which a heat flux under dynamic conditions is transmitted on opposite sides. This obviously implies that the higher the speed is, the lower the time lag is, so the heat takes more time to spread. The Eqs. (1) and (2) confirm this relationship. In Table 1 , one can notice that from material 1 to 11 , the thermal diffusivities are increasing steadily.

Therefore, that fact shows that material 2 has better thermal inertia than material 5 and 10 which induce that building modeled with material $\mathrm{X}$ lead to lower thermal charges so to less energy consumption.

\section{Conclusion}

The results of this investigation show the trends of a bioclimatic building thermal inertia. Indeed, the simulation of walls outside and inside temperatures indicates the magnitude of their time lags. Hence, we came to the conclusion that the lower the thermal diffusivity of walls made of local materials and concrete is, the larger their time lag is. Moreover, their time lag permits to conclude that the local materials and the two materials identified in the literature can largely reduce the energy consumption in Buildings.

\section{Acknowledgements}

We would like to thank FONRID (The National Funds for Research and Innovation) for financing the publication of this article. Acknowledgements go to M. $\mathrm{KY}$ for supplying the vegetal fibers of hibiscus cannabis and the LPCE (Laboratory of physics and chemistry of environment) for providing the thermal characterization devices.

\section{References}

[1] IEA. 2004. "Energy Balances for OECD Countries and Energy Balances for Non-OECD Countries." Energy Statistics for OECD Countries and Energy Statistics for non-OECD Countries, 2004 editions, Paris.

[2] David, Y. K., Toguyeni, O. C., Abdoulaye, O., Jean, K., Yvan, D. and Daniel, R. 2012. "Study of the Influence of Roof Insulation Involving Local Material on Cooling Loads of Houses Built of Clay and Straw." Energy and Buildings 50: 74-80.

[3] Ousmane, C. and David, Y. K. T. 2014. "Eco Insulation Materials: Reduction of Cooling Loads of a House Made of Breeze Block or Laterite in a Dry Climate." Journal of Energy and Power Engineering 8: 1246-50.

[4] Abou, L. 2014. "Thermophysical Characterization of Laterite." PhD. thesis, 2ie-University of Havre.

[5] Energy Efficiency of Air Conditioning in Tropical Climates, Tome I, 2002, table 1.6, pp 7, table 1.10 pp15, table 1.14 pp 16-17.

[6] Marechal, J. E. and Devisme, J. M. 1978. "Thermal Diffusivity of Building Materials: Periodic Signal Method.” 
Annals I.T.B.T.P n0357, January.

[7] Roux, J. J. 1984, "Proposal of Simplified Model for the Study of Thermal Behavior of Buildings." Ph.D. thesis.
INSA de Lyon.

[8] Gallauziaux, T. and Fedullo, D. 2011. The great book of insulation. Eyrolles editions, Paris. 